\title{
Synthesis and in vitro antiproliferative activity of new benzothiazole derivatives
}

\author{
Yaseen A. Al-Soud, ${ }^{1}$ Haitham H. Al-Sa'doni, ${ }^{1}$ Bahjat Saeed, ${ }^{2}$ Ihsan H. Jaber, ${ }^{1}$ \\ Mohammad O. Beni-Khalid, ${ }^{1}$ Najim A. Al-Masoudi, ${ }^{3, *}$ Tahsin Abdul-Kadir, ${ }^{2}$ Paolo La \\ Colla, ${ }^{4}$ Bernardetta Busonera, ${ }^{4}$ Tiziana Sanna, ${ }^{4}$ and Roberta Loddo ${ }^{4}$ \\ ${ }^{1}$ Department of Chemistry, College of Science, University of Al al-Bayt, Al-Mafraq, Jordan \\ ${ }^{2}$ Department of Chemistry, College of Education, University of Basrah, Basrah, Iraq \\ ${ }^{3}$ Fachbereich Chemie, Universität Konstanz, Postfach 5560, D-78457 Konstanz, Germany, \\ (Formerly) \\ ${ }^{4}$ Department of Biomedical Sciences and Technologies, University of Cagliari, Cittadella \\ Universitaria, 09042 Monserrato (CA), Italy \\ E-mail: Najim.Al-Masoudi@gmx.de
}

\begin{abstract}
A series of benzothiazole bearing piperazino-arylsulfonamides (5a-k), and arylthiol analogues $(\mathbf{6 a - j})$ as well as substituted benzothiazoles having sulfonamides (9b, 9l-n and 10) have been synthesized. All compounds were evaluated, in vitro, for their antiproliferative activity against a large panel of human tumor-derived cell lines. Compounds $5 \mathbf{c}, \mathbf{5 d}, \mathbf{5 j}, \mathbf{6 b}, \mathbf{6 c}$ and $\mathbf{6 j}$ were the most potent analogues in this series, showing activity against both cell lines derived from haematological and solid tumors $\left(\mathrm{CC}_{50}\right.$ range $\left.=8-24 \mu \mathrm{M}\right)$, only $\mathbf{5 d}$ was found to be selective and not cytotoxic to normal human tissues.
\end{abstract}

Keywords: Antiproliferative activity, arylthiols, benzothiazoles, sulfonamides

\section{Introduction}

A number of benzothiadiazoles showed selective antiproliferative activity, especially the phenylsubstituted benzothiazoles, ${ }^{1-3}$ while condensed pyrimido benzothiazoles and benzothiazolo quinazolines exert antiviral activity. ${ }^{4}$ Substituted 2-(4-aminophenyl)benzothiazoles were developed and examined, in vitro, for their antiproliferative activity in ovarian, breast, renal and colon carcinoma human cell lines, ${ }^{5-8}$ imidazo benzothiazoles, ${ }^{9,10}$ as well as, polymerized benzothiazoles ${ }^{11}$ and other substituted benzothiazoles ${ }^{12}$ showed remarkable antitumor activity against malignant cell lines. The aryl amines, 2-(4-amino-3-methylphenyl)benzothiazole, ${ }^{13,14}$ 2- 
(4-aminophenyl)-benzothiazole, ${ }^{15}$ the fluoro analogue (5F 203), ${ }^{16}$ 2-(3,4-dimethoxyphenyl)-5fluoro-benzothiazole (1) ${ }^{17}$ are considered as potent ligands for the arylhydrocarbon receptor (AhR) which translocates with the drug to cell nuclei. A further class of benzothiazoles have been synthesized and exhibited potent antitumor activity e.g. benzothiazole-substituted 4hydroxycyclohexadieneone ${ }^{18}$ against renal, colon cancer cell lines and prodrug Phortress, ${ }^{19}$ human mammary tumor xenografs, ${ }^{20}$ and is currently under the pharmacological investigation in phase I clinical trial in the UK. Yoshida et $a .^{21}$ have synthesized a highly potent benzothiazole derivative bearing an amido with that displays excellent in vivo inhibitory effect on tumor growth. Recently, Racane et al. ${ }^{22}$ have described the synthesis of bis-disubstituted amidino benzothiazoles as potential anti HIV agents.

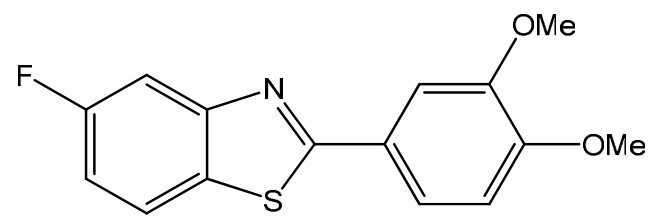

Although the nature of the 2-substituent of benzothiazole backbone (e.g. aryl group in 1) exerts a profound influence on the predominant biotransformation pathway as well as the focus of preclinical interest, but introduction of potential substituents at C-2, such as 4-arylthio piperazine residues, might optimizing the antiproliferative activity and then explain the mechanism of action in comparison with other classes of chemotherapeutic agent or carcinogenic aromatic amines. We report here antiproliferative evaluation of new benzothiazole derivatives bearing (piperazinyl-1-yl)-2-(arylthio)-ethanone for antitumor activity.

\section{Results and Discussion}

Our recent work had focused on preparation of 2-amino-1-(4-(benzo[d]thiazol-2-yl)piperazin-1yl)ethanone (4), ${ }^{23}$ which was prepared from $\mathbf{2}^{24}$ via the chloro derivative $3,{ }^{23}$ as starting material for the synthesis of potentially active analogues. In the present work, amine $\mathbf{4}$ has been selected for the synthesis of new potentially active substituted sulfonamide derivatives. Thus, reaction of 4 with the arylsulphonyl chloride: benzene-, $p$-toulene-, 4-chlorobenzene-, 2,5-dichlorobenzene-, 4-nitrobenzene-, 3-trifluoromethylbenzene-, 4-methoxybenzene-, 8-quinolin-, 2-thiophene-, 2,5dichlorothiophene- and 3-bromo-5-chlorothiophene sulfonyl chlorides afforded the corresponding sulfonamide products 5a-k in 90-96\% yield (Scheme 1).

The structures of the newly synthesized compounds 5a-k were assigned by the ${ }^{1} \mathrm{H},{ }^{13} \mathrm{C}$ NMR, MS which are in agreement with the suggested structures. DEPT experiments were employed to differentiate secondary and quaternary from primary and tertiary carbons. 
<smiles>c1ccc2sc(N3CCNCC3)nc2c1</smiles>

2
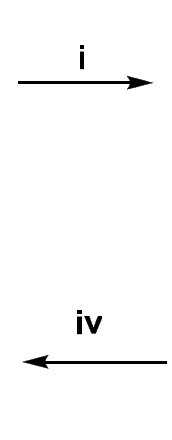

5a-k<smiles>Cc1ccccc1</smiles>

a<smiles>Cc1ccc(C)cc1</smiles>

b<smiles>COc1ccc(C)cc1</smiles><smiles>Cc1cccc2cccnc12</smiles><smiles>Cc1ccc(Cl)cc1</smiles>

c<smiles>Cc1cccs1</smiles>

i<smiles>O=C(CCl)N1CCN(c2nc3ccccc3s2)CC1</smiles>

3

$$
\downarrow \text { ii, iii }
$$<smiles>NCC(=O)N1CCN(c2nc3ccccc3s2)CC1</smiles>

4<smiles>Cc1cc(Cl)ccc1Cl</smiles><smiles>Cc1ccc([N+](=O)[O-])cc1</smiles><smiles>Cc1cccc(C(F)(F)F)c1</smiles>

$$
\text { d }
$$<smiles>Cc1sc(Cl)cc1Br</smiles>

j

k

Scheme 1. Reagents and conditions: (i) 2-Chloroacetyl chloride, Et3N, 23 oC, $\mathrm{CH} 2 \mathrm{Cl} 2,3$ h; (ii) potassium phthalimide, DMF, 120-130 oC, 24 h; (iii) NH2NH2.H2O, reflux, 4 h; (iv) ArSO2Cl, Et3N, CH2Cl2, 23 oC, $20 \mathrm{~h}$

Additional models of benzothiazole derivatives bearing keto substituted piperazine residues were prepared. Thus, treatment of $\mathbf{3}$ with aryl thiols: thiophenol, pyridine-2-thiol, 4methylpyrimidine-2-thiol, 5-methyl-1,3,4-thiadiazole-2-thiol, 1,2,3-triazole-5-thiol, 1-methylimidazole-2-thiol, 1-phenyl-tetrazole-5-thiol, benzo[ $d]$ oxazole-2-thiol, benzo $[d]$ thiazole-2-thiol and benzo[d]imidazole-2-thiol in the presence of $\mathrm{NaH}$ at $23{ }^{\circ} \mathrm{C}$ afforded $\mathbf{6 a - j}$ in $33-86 \%$ yield (Scheme 2). The assignment of protons and carbons of the benzothiazole ring and piperazine were deduced from comparison with compounds $\mathbf{5 a - k}$. The $\mathrm{CH}_{2} \mathrm{~S}$ protons resonated at $\delta$ 4.02$4.45 \mathrm{ppm}$ as a singlet. In the ${ }^{13} \mathrm{C}$ NMR spectra of $\mathbf{6 a - j}, \mathrm{CH}_{2} \mathrm{~S}$ carbon appeared at the region $\delta$ 31.8-37.1 ppm. Resonances at $\delta 24.2,15.7$ and $33.5 \mathrm{pm}$ were assigned to the $\mathrm{CH}_{3}$ carbons of $\mathbf{6 c}$, 6d and 6f, respectively. The higher-field resonances at the region $\delta 168.0-170.0 \mathrm{ppm}$ were attributed to the carbonyl. The carbons of aromatic, pyridine, pyrimidine, thiazole, triazole, imidazole, tetrazole, benzoxazole, benzothiazole, and benzoimidazole conjugated to $\mathrm{CH}_{2} \mathrm{~S}$ group were assigned. 
<smiles>O=C(CCl)N1CCN(c2nc3ccccc3s2)CC1</smiles>

3<smiles>[R]=[Fe]</smiles>

a

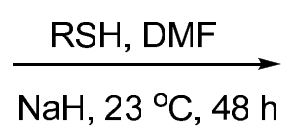

$\mathrm{NaH}, 23^{\circ} \mathrm{C}, 48 \mathrm{~h}$<smiles>[R]CC(=O)N1CCN(c2nc3ccccc3s2)CC1</smiles>

$6 a-j$<smiles>Cc1nccn1C</smiles><smiles>Cc1nnnn1-c1ccccc1</smiles><smiles>Cc1nc2ccccc2o1</smiles><smiles>Cc1nc2ccccc2[nH]1</smiles>

h<smiles>Cc1nc2ccccc2s1</smiles><smiles>Cc1nnc(C)s1</smiles>

d

i<smiles>Cc1cnn[nH]1</smiles>

e

j

\section{Scheme 2}

Further, our work was modified by selecting the 5-ethoxybenzo[d]thiazol-2-amine (7) and its 6-iodo analogue 8 as precursors for the synthesis of new derivatives to examine their antitumor activity in comparison to the sulfonamide analogues 5a-k and 6a-j. Compounds 9b, 9l-n and 10 were prepared in 76, 77, 57, 60 and 70\% yields, respectively from 7 and $\mathbf{8}$ by applying the sulfonylation method used previously in the preparation of 5a-k (Scheme 3). The structures of 9b, 9l-n and 10 were confirmed by their ${ }^{1} \mathrm{H}$ NMR, ${ }^{13} \mathrm{C}$ and mass spectra.<smiles>[R]c1cc2nc(N)sc2cc1[R]</smiles>

7: $\mathrm{R}^{1}=\mathrm{OEt}, \mathrm{R}^{2}=\mathrm{H}$

8: $R^{1}=H, R^{2}=I$

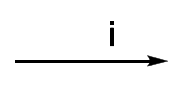<smiles>[R]c1cc2nc(NS(=O)(=O)O)sc2cc1[R]</smiles>

\begin{tabular}{|c|c|c|}
\hline 9 & $\mathrm{R}$ & $\mathrm{R}^{1} \quad \mathrm{R}^{2}$ \\
\hline b & 4-Me-Ph & OEt H \\
\hline I & $2,4-\mathrm{NO}_{2}-\mathrm{Ph}$ & OEt $\mathrm{H}$ \\
\hline m & $\mathrm{CH}_{2} \mathrm{Ph}$ & OEt $\mathrm{H}$ \\
\hline $\mathbf{n}$ & $\mathrm{Me}$ & OEt $\mathrm{H}$ \\
\hline 10 & $2,4-\mathrm{NO}_{2}-\mathrm{Ph}$ & H I \\
\hline
\end{tabular}

Scheme 3. Reagents and conditions: (i) RSO2Cl, Et $3 \mathrm{~N}, \mathrm{CH} 2 \mathrm{Cl} 2,23{ }^{\circ} \mathrm{C}, 20 \mathrm{~h}$ 


\section{In vitro antiproliferative activity}

Compounds 5a-k, 6a-j, 9b, 9l-n and 10 were tested, in vitro, against a large panel of human cell lines derived from hematological $\left[\mathrm{CD}^{+}\right.$human T-cells containing an integrated HTLV-1 genome (MT-4); $\mathrm{CD}^{+}$human acute T-lymphoblastic leukaemia (CCRF-CEM); Human splenic B-lymphoblastoid cells (WIL-2NS); Human acute B-lymphoblastic leukemia (CCRF-SB)] and solid [skin melanoma (SK-28); breast adenocarcinoma (MCF-7); lung squamous carcinoma (SKMES-1); hepatocellular carcinoma (HepG-2); prostate carcinoma (DU-145)] or normal tissues [lung fibroblasts (MRC-5)].

For comparative purposes, we evaluated the cytotoxic activities of the compounds relative to Doxorubicin. As shown in Table 1, the benchmark active compounds were 5c especially against the human prostate carcinoma (DU-145) cell lines $\left(C C_{50}=8 \pm 3 \mu \mathrm{M}\right)$ and $\mathbf{5 d}$ against the human hepatocellular carcinoma (HepG2) and human prostate (DU-145) cell lines $\left(C C_{50}=8 \pm 2 \mu \mathrm{M}, 9 \pm 2\right.$ $\mu \mathrm{M}$, respectively).

Introduction of a chloro-, dichlorophenyl and dichlorothiophene residues in the backbones of $\mathbf{5 c}, \mathbf{5} \mathbf{d}$ and $\mathbf{5 j}$, generally enhanced the potency: dramatic changes in activity were observed with the other congeneres (compounds 5a,b, 5e-i, 5k). Thus, replacement of either (or both) of the chloro groups by hydrogen (5a), methyl (5b), nitro (5e), trifluromethyl (5f), or methoxy (5g) substituents had a deactivating effect. Similarly, the analogues $\mathbf{5 h}, \mathbf{5 i}$ and $\mathbf{5 k}$ having congeneres other than chloro substituent showed only low micromolar inhibitory potency.

All of the piprazino-arylthio analogues $(\mathbf{6 a}-\mathbf{j})$ were found to be markedly less active against the cancer cell lines tested when compared to the lead compound $\mathbf{5 c}, \mathbf{5 d}$ and $\mathbf{5 i}$, except $\mathbf{6 c}$ and $\mathbf{6 j}$, which exhibited activity against both cell lines derived from haematological and solid tumors.

The metabolic biotransformation of $\mathbf{5 b}, \mathbf{5} \mathbf{c}$ and $\mathbf{5 d}$ in human cells might be mediated through the CYP1 family of cytochrome P450s. ${ }^{26}$

Compounds $\mathbf{9 b}, \mathbf{9 l - n}$ and $\mathbf{1 0}$ were found to be inactive against all panels of tumor cell lines $\left(C C_{50}>100 \mu \mathrm{M}\right)$, data not shown. 
Table 1. Antiproliferative activity against haematological and solid human tumor cell lines and "normal human tissues"

\begin{tabular}{|c|c|c|c|c|c|c|c|c|c|c|}
\hline & $\mathrm{CC}_{50}(\mu$ & $\mathrm{M})^{\mathrm{a}}$ & & & & & & & & \\
\hline Entry & $\mathrm{MT}-4^{\mathrm{a}}$ & CCRF-CEM $^{\mathrm{b}}$ & WIL-2NS $^{\mathrm{c}}$ & CCRF-SB $^{d}$ & SK-MEL-28 & $\mathrm{MCF}^{\mathrm{f}}$ & SK-MES-1 ${ }^{\mathrm{g}}$ & HepG $2^{\text {h }}$ & DU145 & MRC $-5^{\mathrm{j}}$ \\
\hline $5 \mathbf{a}$ & $>100$ & $>100$ & $>100$ & $82 \pm 18$ & $>100$ & $29 \pm 2$ & $24 \pm 2$ & $24 \pm 1$ & $18 \pm 3$ & $66 \pm 7$ \\
\hline $5 b$ & $58 \pm 2$ & $28 \pm 5$ & $94 \pm 6$ & $25 \pm 7$ & $23 \pm 3$ & $23 \pm 0.5$ & $21 \pm 4$ & $26 \pm 2$ & $18 \pm 1$ & $>100$ \\
\hline $5 c$ & $>100$ & $13 \pm 4$ & $16 \pm 4$ & $14 \pm 0.5$ & $11 \pm 1$ & $10 \pm 2$ & $12 \pm 0.5$ & $10 \pm 0.5$ & $8 \pm 3$ & $17 \pm 2$ \\
\hline 5d & $16 \pm 1$ & $12 \pm 0.5$ & $24 \pm 0.6$ & $17 \pm 5$ & $21 \pm 3$ & $13 \pm 0.05$ & $18 \pm 2$ & $8 \pm 2$ & $9 \pm 2$ & $>100$ \\
\hline $5 e$ & $>100$ & $>100$ & $82 \pm 10$ & $18 \pm 1$ & $84 \pm 16$ & $90 \pm 10$ & $52 \pm 6$ & $61 \pm 2$ & $18 \pm 2$ & $>100$ \\
\hline $5 f$ & $>100$ & $>100$ & $>100$ & $>100$ & $>100$ & $>100$ & $>100$ & $>100$ & $>100$ & $>100$ \\
\hline $5 g$ & $44 \pm 5$ & $30 \pm 6$ & $91 \pm 5$ & $32 \pm 4$ & $>100$ & $33 \pm 5$ & $29 \pm 2$ & $38 \pm 2$ & $28 \pm 2$ & $>100$ \\
\hline $5 h$ & $>100$ & $>100$ & $>100$ & $>100$ & $>100$ & $>100$ & $>100$ & $>100$ & $>100$ & $>100$ \\
\hline $5 \mathbf{i}$ & $33 \pm 3$ & $39 \pm 8$ & $25 \pm 4$ & $23 \pm 5$ & $>100$ & $22 \pm 0.5$ & $29 \pm 4$ & $23 \pm 0.1$ & $17 \pm 3$ & $>100$ \\
\hline $5 \mathbf{j}$ & $22 \pm 2$ & $13 \pm 1$ & $14 \pm 1$ & $23 \pm 1$ & $13 \pm 0.5$ & $17 \pm 4$ & $12 \pm 0.8$ & $13 \pm 1$ & $11 \pm 1$ & $16 \pm 1$ \\
\hline $5 k$ & $29 \pm 3$ & $21 \pm 0.7$ & $>100$ & $>100$ & $>100$ & $>100$ & $>100$ & $>100$ & $14 \pm 2$ & $82 \pm 18$ \\
\hline $6 a$ & $>100$ & $91 \pm 10$ & $>100$ & $84 \pm 8$ & $90 \pm 10$ & $>100$ & $>100$ & $>100$ & $40 \pm 5$ & 100 \\
\hline $6 b$ & $74 \pm 6$ & $36 \pm 3$ & $60 \pm 9$ & $24 \pm 4$ & $35 \pm 8$ & $52 \pm 2$ & $34 \pm 4$ & $23 \pm 3$ & $26 \pm 4$ & $40 \pm 10$ \\
\hline $6 c$ & $46 \pm 4$ & $12 \pm 2$ & $13 \pm 2$ & $13 \pm 0.5$ & $18 \pm 3$ & $14 \pm 2$ & $19 \pm 0.5$ & $17 \pm 2$ & $17 \pm 1.5$ & $24 \pm 4$ \\
\hline $6 d$ & $>100$ & $>100$ & $>100$ & $>100$ & $>100$ & $>100$ & $>100$ & $>100$ & $>100$ & $>100$ \\
\hline $6 e$ & $>100$ & $16 \pm 6$ & $50 \pm 10$ & $\geq 100$ & $>100$ & $>100$ & $>100$ & $>100$ & $>100$ & $>100$ \\
\hline $6 f$ & $79 \pm 9$ & $39 \pm 0.1$ & $85 \pm 15$ & $80 \pm 20$ & $38 \pm 1$ & $61 \pm 1$ & $32 \pm 0.3$ & $34 \pm 5$ & $25 \pm 2$ & 62 \\
\hline $6 g$ & $>100$ & $>100$ & $>100$ & $>100$ & $>100$ & $>100$ & $>100$ & $>100$ & $>100$ & $>100$ \\
\hline $6 h$ & $>100$ & $74 \pm 5$ & $>100$ & $61 \pm 9$ & $75 \pm 8$ & $87 \pm 13$ & $80 \pm 20$ & $73 \pm 3$ & $67 \pm 13$ & $80 \pm 10$ \\
\hline $6 i$ & $40 \pm 2$ & $21 \pm 4$ & $46 \pm 12$ & $30 \pm 6$ & $\geq 100$ & $>100$ & $90 \pm 6$ & $>100$ & $80 \pm 20$ & $>100$ \\
\hline $6 \mathbf{j}$ & $>100$ & $17 \pm 2$ & $19 \pm 1.5$ & $29 \pm 9$ & $19 \pm 1.5$ & $17 \pm 3$ & $19 \pm 1$ & $13 \pm 0.2$ & $14 \pm 3$ & $>100$ \\
\hline Doxorub-Icin ${ }^{\mathrm{k}}$ & 0.01 & 0.02 & 0.02 & 0.03 & & & & & & \\
\hline
\end{tabular}

${ }^{\mathrm{a}}$ Compound concentration required to reduce cell proliferation by $50 \%$, as determined by the MTT method, under conditions allowing untreated controls to undergo at least three consecutive rounds of multiplication. Data represent mean values $( \pm \mathrm{SD})$ for three independent determinations. ${ }^{\mathrm{a}}$ $\mathrm{CD}^{+}$human T-cells containing an integrated HTLV-1 genome. ${ }^{\mathrm{b}} \mathrm{CD} 4{ }^{+}$human acute T-lymphoblastic leukaemia. ${ }^{\mathrm{c}}$ human splenic B-lymphoblastoid cells ${ }^{\mathrm{d}}$ human acute B-lymphoblastic. ${ }^{\mathrm{e}}$ human skin melanoma. ${ }^{\mathrm{f}}$ human breast adenocarcinoma. ${ }^{\mathrm{g}}$ human lung squamous carcinoma. ${ }^{\mathrm{h}}$ human hepatocellular carcinoma. ${ }^{\mathrm{i}}$ human prostate carcinoma. ${ }^{\mathrm{j}}$ human lung fibroblasts. ${ }^{\mathrm{k}}$ control. 
In conclusion, we report the synthesis and in vitro biological evaluation of new benzothiazole derivatives as potential cytotoxic agents. The first results confirm the identification of the chlorinated-arylsulphonamide $N$-(2-(4-(benzo[d]thiazol-2-yl)piperazin-1-yl)-2-oxoethyl) structure as a new antiproliferative pharmacophore, with the 4-chloro and 2,5dichlorophenylsuphonamide or 2,5-dichlorothiophene analogues (5c, $\mathbf{5 d}$ and $\mathbf{5 j}$ ) being the agents of choice for further pharmacological evaluation. Further experiments aimed at defining the target and the mechanisms of the inhibitory effect showed by these molecules are in progress and the results will be reported in a forthcoming paper.

\section{Experimental Section}

General Procedures. Melting points are uncorrected and were measured on a Büchi melting point apparatus B-545 (Büchi Labortechnik AG, Switzerland). Microanalytical data were obtained with a Vario, Elemental apparatus (Shimadzu, Japan). NMR spectra were recorded on $300 \mathrm{MHz}\left({ }^{1} \mathrm{H}\right)$ and on $75 \mathrm{MHz}\left({ }^{13} \mathrm{C}\right)$ spectrometers (Bruker, Germany) with TMS as internal standard and on the $\delta$ scale in ppm. Mass spectra were recorded at $70 \mathrm{eV}$ on EI. Silica gel $(0.040-0.063 \mathrm{~mm})$ used for column chromatography and analytical silica gel TLC plates 60 F254 were purchased from Merck.

General procedure for the preparation of $\mathrm{N}$-(2-(4-(benzo[d]thiazol-2-yl)piperazin-1-yl)-2oxoethyl)arylsulfonamides (5a-k)

A solution of $4(1.00 \mathrm{mmol})$ and an arylsulfonyl chloride (a-k) $(1.00 \mathrm{mmol})$ in $\mathrm{CH}_{2} \mathrm{Cl}_{2}(50 \mathrm{~mL})$ containing $\mathrm{Et}_{3} \mathrm{~N}(0.1 \mathrm{~mL}, 1.00 \mathrm{mmol})$ was stirred at $23{ }^{\circ} \mathrm{C}$ for $20 \mathrm{~h}$. The solvent was evaporated to dryness and the residue was purified on thin layer chromatography, using $\mathrm{CHCl}_{3}-\mathrm{MeOH}$ (30:1) as eluent to give the desired product, which recrystallized from EtOH.

$\mathrm{N}$-(2-(4-(Benzo[d] thiazol-2-yl)piperazin-1-yl)-2-oxo-ethyl)benzenesulfonamide (5a). From a (0.18 g). Yield: $0.39 \mathrm{~g}(93 \%)$; mp $175-177{ }^{\circ} \mathrm{C} .{ }^{1} \mathrm{H}$ NMR (DMSO- $\left.d_{6}\right): \delta 3.52$ (brs., $8 \mathrm{H}, H_{\text {piperazine }}$ ); $3.82\left(\mathrm{~s}, 2 \mathrm{H}, \mathrm{CH}_{2} \mathrm{C}=\mathrm{O}\right) ; 7.08-7.61\left(\mathrm{~m}, 9 \mathrm{H}, H_{\text {arom }}\right), 7.63$ (brs., $\left.1 \mathrm{H}, \mathrm{NH}\right) .{ }^{13} \mathrm{C} \mathrm{NMR}\left(\mathrm{DMSO}-d_{6}\right): \delta$ $41.1\left(\mathrm{NHCH}_{2}\right) ; 43.9,44.4,47.9,48.2$ ( $\left.C_{\text {piperazine}}\right) ; 119.1,121.9,126.5,127.1,129.5,130.9,132.9$ $\left(C_{\text {arom }}\right) ; 140.9\left(C_{\text {arom }}-\mathrm{SO}_{2}\right) ; 152.7\left(C_{\text {benzothiazole }}^{3 \mathrm{a}}\right) ; 166.4(\mathrm{C}=\mathrm{O}) ; 168.5(\mathrm{C}=\mathrm{N})$. Anal. calcd. for $\mathrm{C}_{19} \mathrm{H}_{20} \mathrm{~N}_{4} \mathrm{O}_{3} \mathrm{~S}_{2}$ : C, 56.50; H, 5.84; N, 20.27. Found: C, 56.28; H, 5.92; N, 20.48. m/z (EI) 416 $(\mathrm{M})^{+}$.

N-(2-(4-(Benzo[ $[d]$ thiazol-2-yl)piperazin-1-yl)-2-oxo-ethyl)-4-methylbenzenesulfonamide (5b). From b $(0.19 \mathrm{~g})$. Yield: $0.40 \mathrm{~g}(94 \%)$; mp 180-183 ${ }^{\circ} \mathrm{C} .{ }^{1} \mathrm{H} \mathrm{NMR}\left(\mathrm{CDCl}_{3}\right): \delta 2.43(\mathrm{~s}, 3 \mathrm{H}$, $\left.\mathrm{CH}_{3}\right) ; 3.52-3.76\left(\mathrm{~m}, 8 \mathrm{H}, H_{\text {piperazine}}\right) ; 3.81$ (s, $\left.2 \mathrm{H}, \mathrm{CH}_{2} \mathrm{C}=\mathrm{O}\right) ; 5.66$ (brs., $\left.1 \mathrm{H}, \mathrm{NH}\right) ; 7.33$ (d, $J=7.8$ $\left.\mathrm{Hz}, 2 \mathrm{H}, H_{\text {arom }}\right) ; 7.35-7.65\left(\mathrm{~m}, 4 \mathrm{H}, H_{\text {arom }}\right) ; 7.78\left(\mathrm{~d}, J=7.8 \mathrm{~Hz}, 2 \mathrm{H}, H_{\text {arom }}\right) .{ }^{13} \mathrm{C} \mathrm{NMR}\left(\mathrm{CDCl}_{3}\right): \delta$ $21.4\left(\mathrm{CH}_{3}\right) ; 41.2\left(\mathrm{NHCH}_{2}\right) ; 43.9,47.2,48.0,48.1$ ( $\left.C_{\text {piperazine }}\right) ; 118.9,121.9,122.1,126.7,129.9$, $130.4\left(C_{\text {arom }}\right) ; 137.9\left(C_{\text {arom }}-\mathrm{SO}_{2}\right) ; 143.1\left(C_{\text {arom-Me }}^{4}\right) ; 151.9\left(C_{\text {benzothiazole }}^{3 \mathrm{a}}\right) ; 166.5(\mathrm{C}=\mathrm{O}) ; 168.5$ 
$(\mathrm{C}=\mathrm{N})$. Anal. calcd. for $\mathrm{C}_{20} \mathrm{H}_{22} \mathrm{~N}_{4} \mathrm{O}_{3} \mathrm{~S}_{2}: \mathrm{C}, 55.79 ; \mathrm{H}, 5.15 ; \mathrm{N}, 13.01$. Found: $\mathrm{C}, 55.92 ; \mathrm{H}, 4.97 ; \mathrm{N}$, 13.11. $\mathrm{m} / z(\mathrm{EI}) 430(\mathrm{M})^{+}$.

$N$-(2-(4-(Benzo $[d]$ thiazol-2-yl)piperazin-1-yl)-2-oxo-ethyl)-4-chlorobenzenesulfonamide (5c). From c $(0.21 \mathrm{~g})$. Yield: $0.42 \mathrm{~g}(94 \%)$; mp 165-167 ${ }^{\circ} \mathrm{C} .{ }^{1} \mathrm{H}$ NMR (DMSO- $\left.d_{6}\right): \delta 3.52$ (brs., $\left.8 \mathrm{H}, H_{\text {piperazine }}\right) ; 3.85\left(\mathrm{~s}, 2 \mathrm{H}, \mathrm{CH}_{2} \mathrm{C}=\mathrm{O}\right) ; 7.06-7.48\left(\mathrm{~m}, 3 \mathrm{H}, H_{\text {arom }}\right), 7.65\left(\mathrm{~d}, J=7.0 \mathrm{~Hz}, 2 \mathrm{H}, H_{\text {arom }}\right)$; $7.76\left(\mathrm{~d}, J=6.8 \mathrm{~Hz}, 1 \mathrm{H}, H_{\text {arom }}\right) ; 7.84$ (d, $\left.J=7.0 \mathrm{~Hz}, 2 \mathrm{H}, H_{\text {arom}}\right) ; 7.93$ (brs., $\left.1 \mathrm{H}, \mathrm{NH}\right) .{ }^{13} \mathrm{C} \mathrm{NMR}$ $\left(\mathrm{DMSO}-d_{6}\right): \delta 41.2\left(\mathrm{NHCH}_{2}\right) ; 41.9,44.3,48.0,48.2\left(C_{\text {piperazine})}\right) ; 119.2,121.3,121.9,126.5$, 129.1, 129.6, $\left.130.9 C_{\text {arom }}\right) ; 139.9\left(C_{\text {arom-Cl }}^{4}\right) ; 142.0\left(C_{\text {arom }}-\mathrm{SO}_{2}\right) ; 152.7\left(C_{\text {benzothiazole }}^{3 \mathrm{a}}\right) ; 166.4$ $(\mathrm{C}=\mathrm{O}) ; 168.5(\mathrm{C}=\mathrm{N})$. Anal. calcd. for $\mathrm{C}_{19} \mathrm{H}_{19} \mathrm{ClN}_{4} \mathrm{O}_{3} \mathrm{~S}_{2}: \mathrm{C}, 50.60 ; \mathrm{H}, 4.25 ; \mathrm{N}, 12.42$. Found: $\mathrm{C}$, $50.81 ; \mathrm{H}, 4.50 ; \mathrm{N}, 12.30 . \mathrm{m} / z$ (EI) $450 / 452$.

$\mathrm{N}$-(2-(4-(Benzo[d]thiazol-2-yl)piperazin-1-yl)-2-oxo-ethyl)-2,5-dichlorobenzenesulfonamide (5d). From d (0.25 g). Yield: $0.46 \mathrm{~g}(95 \%)$; mp 156-159 ${ }^{\circ} \mathrm{C} .{ }^{1} \mathrm{H}$ NMR (DMSO- $\left.d_{6}\right): \delta 3.52$ (br s., $\left.8 \mathrm{H}, H_{\text {piperazine }}\right) ; 4.04\left(\mathrm{~s}, 2 \mathrm{H}, \mathrm{CH}_{2} \mathrm{C}=\mathrm{O}\right) ; 7.08-7.98\left(\mathrm{~m}, 7 \mathrm{H}, \mathrm{H}_{\text {arom }}\right), 8.12$ (brs, $\left.1 \mathrm{H}, \mathrm{NH}\right) .{ }^{13} \mathrm{C} \mathrm{NMR}$ $\left(\mathrm{DMSO}-d_{6}\right): 41.2\left(\mathrm{NHCH}_{2}\right)$; 43.9, 44.7, 48.0, 48.2 ( $\left.C_{\text {piperazine }}\right) ; 119.2,121.1,126.5,129.9,130.2$, $130.9,132.2\left(C_{\text {arom }}\right) ; 133.8\left(C_{\text {arom-Cl }}^{2}\right), 140.6\left(C_{\text {arom-Cl }}^{4}\right) ; 152.7\left(C_{\text {benzothiazole }}^{3 \text { a }}\right) ; 166.6(\mathrm{C}=\mathrm{O}) ; 168.5$ $(\mathrm{C}=\mathrm{N})$. Anal. calcd. for $\mathrm{C}_{19} \mathrm{H}_{18} \mathrm{Cl}_{2} \mathrm{~N}_{4} \mathrm{O}_{3} \mathrm{~S}_{2}: \mathrm{C}, 47.01 ; \mathrm{H}, 3.74 ; \mathrm{N}, 11.54$. Found: $\mathrm{C}, 46.88 ; \mathrm{H}, 3.90$; $\mathrm{N}, 11.76 . m / z$ (EI) $484 / 486(\mathrm{M})^{+}$.

$\mathrm{N}$-(2-(4-(Benzo[d] thiazol-2-yl)piperazin-1-yl)-2-oxo-ethyl)-4-nitrobenzenesulfonamide (5e).

From e (0.22 g). Yield: $0.44 \mathrm{~g}(96 \%) ; \mathrm{mp} 182-185{ }^{\circ} \mathrm{C} .{ }^{1} \mathrm{H}$ NMR (DMSO- $\left.d_{6}\right): \delta 3.51$ (brs., $8 \mathrm{H}$, $\left.H_{\text {piperazine }}\right) ; 3.95$ (s, 2H, $\left.\mathrm{CH}_{2} \mathrm{C}=\mathrm{O}\right) ; 7.06-7.80$ (m, $\left.4 \mathrm{H}, H_{\text {arom }}\right), 8.09$ (d, J=7.0 Hz, $\left.2 \mathrm{H}, H_{\text {arom }}\right) ; 8.26$ (br s., $1 \mathrm{H}, \mathrm{NH}) ; 8.39\left(\mathrm{~d}, J=7.0 \mathrm{~Hz}, 2 \mathrm{H}, H_{\text {arom }}\right) .{ }^{13} \mathrm{C}$ NMR (DMSO- $\left.d_{6}\right): \delta 41.2\left(\mathrm{NHCH}_{2}\right) ; 43.9$, $44.4,48.0,48.2$ ( $\left.C_{\text {piperazine }}\right) ; 119.2,121.7,121.9,124.8,126.5,128.7,130.9$ ( $\left.C_{\text {arom }}\right) ; 146.8$ $\left(C_{\text {arom-NO2 }}^{2}\right) ; 149.9\left(C_{\text {arom }}-\mathrm{SO}_{2}\right) ; 152.7\left(C^{3 \mathrm{a}}\right.$ benzothiazole $) ; 166.3(\mathrm{C}=\mathrm{O}) ; 168.5(\mathrm{C}=\mathrm{N})$. Anal. calcd. for $\mathrm{C}_{19} \mathrm{H}_{19} \mathrm{~N}_{5} \mathrm{O}_{5} \mathrm{~S}_{2}$ : C, 49.45; H, 4.15; N, 15.17. Found: C, 49.30; H, 4.22; N, 15.43. $\mathrm{m} / z$ (EI) 461 $(\mathrm{M})^{+}$.

N-(2-(4-(Benzo[d]thiazol-2-yl)piperazin-1-yl)-2-oxo-ethyl)-3-(trifluoromethyl)benzenesulfonamide (5f). From f (0.24 g). Yield: $0.44 \mathrm{~g}(91 \%)$; mp 194-196 ${ }^{\circ} \mathrm{C}$. ${ }^{1} \mathrm{H}$ NMR (DMSO- $\left.d_{6}\right): \delta$ 3.52 (brs., $8 \mathrm{H}, H_{\text {piperazine }}$ ); 3.93 (s, $2 \mathrm{H}, \mathrm{CH}_{2} \mathrm{C}=\mathrm{O}$ ); 7.08-8.03 (m, 8H, $\left.H_{\text {arom }}\right), 8.15$ (br s., $\left.1 \mathrm{H}, \mathrm{NH}\right)$. ${ }^{13} \mathrm{C}$ NMR (DMSO- $\left.d_{6}\right): 41.2\left(\mathrm{NHCH}_{2}\right) ; 43.9,44.4,48.0,48.2\left(C_{\text {piperazine}}\right) ; 119.2,121.7,121.9$, $123.9,126.5,129.4,129.5,129.9,130.9,131.0,131.2\left(C_{\text {arom }}+C F_{3}\right) ; 142.4\left(C_{\text {arom }}+\mathrm{SO}_{2}\right) ; 152.7$ $\left(C^{3 \mathrm{a}}\right.$ benzothiazole $) ; 166.3(\mathrm{C}=\mathrm{O}) ; 168.5(\mathrm{C}=\mathrm{N})$. Anal. calcd. for $\mathrm{C}_{20} \mathrm{H}_{19} \mathrm{~F}_{3} \mathrm{~N}_{4} \mathrm{O}_{3} \mathrm{~S}_{2}: \mathrm{C}, 49.58 ; \mathrm{H}, 3.95$; $\mathrm{N}, 11.65$. Found: C, 49.74; H, 4.18; N, 11.75. $\mathrm{m} / \mathrm{z}(\mathrm{EI}) 483 / 485(\mathrm{M})^{+}$.

$\mathrm{N}$-(2-(4-(Benzo $[\boldsymbol{d}]$ thiazol-2-yl)piperazin-1-yl)-2-oxo-ethyl)-4-methoxybenzenesulfonamide (5g). From g (0.21 g). Yield: 0.49 g (91\%); mp 150-152 ${ }^{\circ} \mathrm{C} .{ }^{1} \mathrm{H}$ NMR (DMSO- $\left.d_{6}\right): \delta 3.53$ (brs., $\left.8 \mathrm{H}, H_{\text {piperazine }}\right) ; 3.77\left(\mathrm{~s}, 2 \mathrm{H}, \mathrm{CH}_{2} \mathrm{C}=\mathrm{O}\right) ; 3.81\left(\mathrm{~s}, 3 \mathrm{H}, \mathrm{OCH}_{3}\right) ; 7.09\left(\mathrm{~d}, J=7.0 \mathrm{~Hz}, 2 \mathrm{H}, H_{\text {arom }}\right)$; 7.26$7.49\left(\mathrm{~m}, 4 \mathrm{H}, H_{\text {arom }}\right) ; 7.58(\mathrm{~s}, 1 \mathrm{H}, \mathrm{NH}) ; 7.77\left(\mathrm{~d}, J=7.0 \mathrm{~Hz}, 2 \mathrm{H}, H_{\text {arom }}\right) .{ }^{13} \mathrm{C}$ NMR (DMSO- $\left.d_{6}\right): \delta$ $41.2\left(\mathrm{NHCH}_{2}\right) ; 44.0,44.5, .48 .0,48.2\left(C_{\text {piperazine }}\right) ; 56.1\left(\mathrm{OCH}_{3}\right) ; 114.7,119.2,121.7,121.9$, 126.5, 129.4, 130.9, $132.4\left(C_{\text {arom }}\right) ; 152.7$ ( $\left.C_{\text {benzothiazole }}^{3 \mathrm{a}}\right) ; 162.6\left(C_{\text {arom }}-\mathrm{OMe}\right) ; 166.5(\mathrm{C}=\mathrm{O}) ; 168.5$ $(\mathrm{C}=\mathrm{N})$. Anal. calcd. for $\mathrm{C}_{20} \mathrm{H}_{22} \mathrm{~N}_{4} \mathrm{O}_{4} \mathrm{~S}_{2}: \mathrm{C}, 53.79 ; \mathrm{H}, 4.97 ; \mathrm{N}, 12.55$. Found: $\mathrm{C}, 53.51 ; \mathrm{H}, 4.84 ; \mathrm{N}$, 12.49. $\mathrm{m} / z$ (EI) $446(\mathrm{M})^{+}$. 
N-(2-(4-(Benzo[d]thiazol-2-yl)piperazin-1-yl)-2-oxo-ethyl)quinoline-8-sulfonamide

(5h). From h $(0.23 \mathrm{~g})$. Yield: $0.42 \mathrm{~g}(90 \%)$; mp 205-208 ${ }^{\circ} \mathrm{C} .{ }^{1} \mathrm{H}$ NMR (DMSO- $\left.d_{6}\right): \delta 3.44$ (brs., 8H, $\left.H_{\text {piperazine }}\right) ; 3.53\left(\mathrm{~s}, 2 \mathrm{H}, \mathrm{CH}_{2} \mathrm{C}=\mathrm{O}\right) ; 7.07-8.57\left(\mathrm{~m}, 9 \mathrm{H}, H_{\text {arom }}+\mathrm{NH}\right) ; 9.08(\mathrm{~d}, 1 \mathrm{H}, J=5.0 \mathrm{~Hz}$, $H_{\text {quinolin }) .}{ }^{13} \mathrm{C}$ NMR (DMSO- $\left.d_{6}\right): \delta 41.1\left(\mathrm{NHCH}_{2}\right) ; 43.6,44.8,47.9,48.0\left(C_{\text {piperazine }}\right) ; 119.2$, $121.7,121.9,123.0,126.2,126.5,129.0,130.8,131.0,134.2,136.3,137.6\left(C_{\text {arom }}+C_{\text {quinolin }}\right)$; $143.2\left(C_{\text {quinolin }}^{8 \mathrm{a}}\right) ; 151.8\left(C_{\text {quinolin }}^{2}\right) ; 152.7\left(C^{3 \mathrm{a}}\right.$ benzothiazole $) ; 166.4(\mathrm{C}=\mathrm{O}) ; 168.4(\mathrm{C}=\mathrm{N})$. Anal. calcd. for $\mathrm{C}_{22} \mathrm{H}_{21} \mathrm{~N}_{5} \mathrm{O}_{3} \mathrm{~S}_{2}$ : C, 56.51; H, 4.53; N, 14.98. Found: C, 56.80; H, 4.44; N, 14.67. $\mathrm{m} / z$ (EI) 467 $(\mathrm{M})^{+}$.

N-(2-(4-(Benzo $[d]$ thiazol-2-yl)piperazin-1-yl)-2-oxo-ethyl)thiophene-2-sulfonamide

(5i). From i (0.18 g). Yield: $0.41 \mathrm{~g}(96 \%)$; mp 115-118 ${ }^{\circ} \mathrm{C}$. ${ }^{1} \mathrm{H}$ NMR (DMSO- $\left.d_{6}\right): \delta 3.35$ (brs., 8H, $\left.H_{\text {piperazine }}\right) ; 3.90\left(\mathrm{~s}, 2 \mathrm{H}, \mathrm{CH}_{2} \mathrm{C}=\mathrm{O}\right) ; 7.06-7.93\left(\mathrm{~m}, 7 \mathrm{H}, H_{\text {arom }}\right) ; 8.02(\mathrm{~s}, 1 \mathrm{H}, \mathrm{NH}) .{ }^{13} \mathrm{C} \mathrm{NMR}$ $\left(\mathrm{DMSO}-d_{6}\right): \delta 41.2\left(\mathrm{NHCH}_{2}\right) ; 44.0,44.6,48.0,48.3\left(C_{\text {piperazine }}\right) ; 119.1,121.8,121.9,126.5$, 128.1, 130.7, 132.3, 133.0, $141.6\left(C_{\text {arom }}+C_{\text {thiophene }}\right) ; 152.5\left(C_{\text {benzothiazole }}^{3 \mathrm{a}}\right) ; 166.3(\mathrm{C}=\mathrm{O}) ; 168.5$ $(\mathrm{C}=\mathrm{N})$. Anal. calcd. for $\mathrm{C}_{17} \mathrm{H}_{18} \mathrm{~N}_{4} \mathrm{O}_{3} \mathrm{~S}_{3}: \mathrm{C}, 48.32 ; \mathrm{H}, 4.29 ; \mathrm{N}, 13.26$. Found: $\mathrm{C}, 48.46 ; \mathrm{H}, 4.05 ; \mathrm{N}$, 13.11. $\mathrm{m} / z(\mathrm{EI}) 422(\mathrm{M})^{+}$.

N-(2-(4-(Benzo[d] thiazol-2-yl)piperazin-1-yl)-2-oxo-ethyl)-2,5-dichlorothiophene-3sulfonamide (5j). From j (0.25 g). Yield: 0.46 g (94\%); m.p. 120-122 ${ }^{\circ} \mathrm{C}$. ${ }^{1} \mathrm{H}$ NMR (DMSO- $\left.d_{6}\right)$ :

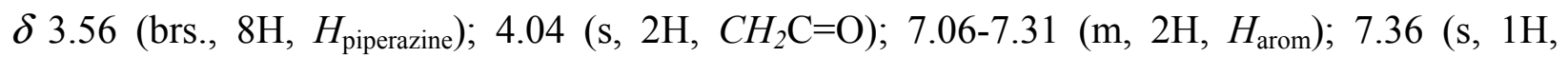
$\left.H_{\text {thiophene }}\right) ; 7.47$ (d, $\left.J=8 \mathrm{~Hz}, 1 \mathrm{H}, H_{\text {arom }}\right) ; 7.78\left(\mathrm{~d}, \mathrm{~J}=8 \mathrm{~Hz}, 1 \mathrm{H}, H_{\text {arom }}\right) ; 8.25(\mathrm{~s}, 1 \mathrm{H}, \mathrm{NH}) .{ }^{13} \mathrm{C}$ NMR (DMSO- $\left.d_{6}\right): \delta 41.3\left(\mathrm{NHCH}_{2}\right) ; 43.9,44.1,48.0,48.2\left(C_{\text {piperazine }}\right) ; 119.2,121.7,122.0$, $126.2,126.6,127.4,129.2,130.8,137.6\left(C_{\text {arom }}+C_{\text {thiophene }}\right) ; 152.6\left(C_{\text {benzothiazole }}^{3 \mathrm{a}}\right) ; 166.4(\mathrm{C}=\mathrm{O})$; $168.6(\mathrm{C}=\mathrm{N})$. Anal. calcd. for $\mathrm{C}_{17} \mathrm{H}_{16} \mathrm{Cl}_{2} \mathrm{~N}_{4} \mathrm{O}_{3} \mathrm{~S}_{3}$ : C, 41.55; H, 3.28; N, 11.40. Found: C, 41.27; $\mathrm{H}, 3.46 ; \mathrm{N}, 11.27 . \mathrm{m} / z$ (EI) 490/492 (M) ${ }^{+}$.

$\mathrm{N}$-(2-(4-(Benzo[d] thiazol-2-yl)piperazin-1-yl)-2-oxoethyl)-3-bromo-5-chlorothiophene-2sulfonamide (5k). From k (0.30 g). Yield: $0.51 \mathrm{~g}(96 \%)$; mp 175-177 ${ }^{\circ} \mathrm{C}$. ${ }^{1} \mathrm{H}$ NMR (DMSO- $\left.d_{6}\right)$ : $\delta 3.55$ (brs, $\left.8 \mathrm{H}, H_{\text {piperazine }}\right) ; 4.07\left(\mathrm{~s}, 2 \mathrm{H}, \mathrm{CH}_{2} \mathrm{C}=\mathrm{O}\right) ; 7.06-7.49\left(\mathrm{~m}, 4 \mathrm{H}, H_{\text {arom }}+H_{\text {thiophene }}\right) ; 7.78(\mathrm{~d}, J$ $\left.=8 \mathrm{~Hz}, 1 \mathrm{H}, H_{\text {arom }}\right) ; 8.43(\mathrm{~s}, 1 \mathrm{H}, \mathrm{NH}) .{ }^{13} \mathrm{C} \mathrm{NMR}\left(\mathrm{DMSO}-d_{6}\right): \delta 41.3\left(\mathrm{NHCH}_{2}\right) ; 43.9,44.6,48.0$, $48.2\left(C_{\text {piperazine }}\right)$; $112.6\left(C_{\text {thioph }}-\mathrm{Br}\right), 119.2,121.7,121.9,126.5,130.9,132.7,134.4,136.4\left(C_{\text {arom }}+\right.$ $\left.C_{\text {thiophene }}\right) ; 152.7\left(C_{\text {benzothiazole }}^{3 \mathrm{a}}\right) ; 166.3(\mathrm{C}=\mathrm{O}) ; 168.5(\mathrm{C}=\mathrm{N})$. Anal. calcd. for $\mathrm{C}_{17} \mathrm{H}_{16} \mathrm{BrClN}_{4} \mathrm{O}_{3} \mathrm{~S}_{3}$ : C, 38.10; H, 3.01; N, 10.45. Found: C, 38.39; H, 3.22; N, 10.70. $\mathrm{m} / z$ (EI) 535/537 (M) ${ }^{+}$.

General procedure for preparation of 1-(4-(benzothiazol-2-yl)piperazinyl-1-yl)-2-(arylthio)ethanone (6a-j)

To a stirred solution of $4(1.00 \mathrm{mmol})$ in DMF $(10 \mathrm{~mL})$ was added $60 \% \mathrm{NaH}(1.0 \mathrm{mmol})$. After $15 \mathrm{~min}$, the arylthiol $(1.00 \mathrm{mmol})$ was added with stirring at $23{ }^{\circ} \mathrm{C}$ for $48 \mathrm{~h}$. The solution was evaporated to dryness and the residue was extracted into $\mathrm{CH}_{2} \mathrm{Cl}_{2}(3 \times 15 \mathrm{~mL})$ and the organic solution was washed with water $(2 \times 20 \mathrm{~mL})$, dried with $\mathrm{Na}_{2} \mathrm{SO}_{4}$ and concentrated under reduced pressure to obtain the product which purified using thin layer chromatography $\left(\mathrm{CHCl}_{3}-\mathrm{MeOH}\right)$. The products were recrystallized from $\mathrm{EtOH}$. 
1-(4-(Benzo $[d]$ thiazol-2-yl)piperazin-1-yl)-2-(phenylthio)ethanone (6a). From a (0.18 g). Yield: $0.31 \mathrm{~g}(83 \%) ; \mathrm{mp} 215-217{ }^{\circ} \mathrm{C} .{ }^{1} \mathrm{H} \mathrm{NMR}\left(\mathrm{CDCl}_{3}\right): \delta 3.55-3.69\left(\mathrm{~m}, 8 \mathrm{H}, H_{\text {piperazine }}\right), 4.07$ (s, $\left.2 \mathrm{H}, \mathrm{SCH}_{2}\right), 7.09-7.77\left(\mathrm{~m}, 9 \mathrm{H}, H_{\text {arom }}\right) .{ }^{13} \mathrm{C} \mathrm{NMR}\left(\mathrm{CDCl}_{3}\right): \delta 36.1\left(\mathrm{SCH}_{2}\right) ; 41.6,45.5,48.7,49.1$ $\left(C_{\text {piperazine }}\right) ; 119.2,121.7,121.9,126.5,126.5,129.0,129.1,129.4,130.9\left(C_{\text {arom }}\right) ; 136.1\left(C_{\text {arom }}-\mathrm{S}\right)$; $152.7\left(C_{\text {benzothiazole }}^{3 \mathrm{a}}\right) ; 167.0(\mathrm{C}=\mathrm{N}) ; 168.5(\mathrm{C}=\mathrm{O})$. Anal. calcd. for $\mathrm{C}_{19} \mathrm{H}_{19} \mathrm{~N}_{3} \mathrm{OS}_{2}: \mathrm{C}, 61.67 ; \mathrm{H}$, 5.18; N, 11.37. Found: C, 61.37; H, 5.06; N, 11.17. $\mathrm{m} / z(\mathrm{EI}) 369(\mathrm{M})^{+}$.

1-(4-(Benzo $[d]$ thiazol-2-yl)piperazin-1-yl)-2-(pyridin-2-ylthio)ethanone (6b). From b (0.18 g). Yield: $0.21 \mathrm{~g}(58 \%) ; \mathrm{mp} 150-152{ }^{\circ} \mathrm{C} .{ }^{1} \mathrm{H} \mathrm{NMR}\left(\mathrm{CDCl}_{3}\right): \delta 3.63-3.98\left(\mathrm{~m}, 8 \mathrm{H}, H_{\text {piperazine }}\right), 4.24$ (s, 2H, $\left.\mathrm{SCH}_{2}\right), 7.02-8.44\left(\mathrm{~m}, 8 \mathrm{H}, H_{\text {arom }}\right) .{ }^{13} \mathrm{C} \mathrm{NMR}\left(\mathrm{CDCl}_{3}\right): \delta 31.8\left(\mathrm{SCH}_{2}\right) ; 41.6,45.6,48.3$, 48.6 ( $\left.\left.C_{\text {piperazine }}\right) ; 119.2,120.0,120.8,122.1,122.3,126.4\left(C_{\text {arom }}+C_{\text {pyridine }}\right) ; 136.5 C_{\text {pyridine }}^{4}\right) ; 149.2$ $\left(C_{\text {pyridine }}^{6}\right) ; 152.7\left(C_{\text {benzothiazole }}^{3 \mathrm{a}}\right) ; 159.1\left(C_{\text {pyridine-S }}^{2}\right), 167.8(\mathrm{C}=\mathrm{N}) ; 168.3(\mathrm{C}=\mathrm{O})$. Anal. calcd. for $\mathrm{C}_{18} \mathrm{H}_{18} \mathrm{~N}_{4} \mathrm{OS}_{2}$ : C, 58.35; H, 4.90; N, 15.12. Found: C, 58.32; H, 4.72; N, 14.92. $\mathrm{m} / \mathrm{z}$ (EI) 370 $(\mathrm{M})^{+}$.

1-(4-(Benzo $[d]$ thiazol-2-yl)piperazin-1-yl)-2-(4-methylpyrimidin-2-ylthio)ethanone(6c).

From c (0.19 g). Yield: $0.27 \mathrm{~g}(70 \%)$; mp 236-238 ${ }^{\circ} \mathrm{C} .{ }^{1} \mathrm{H} \mathrm{NMR}\left(\mathrm{CDCl}_{3}\right): \delta 2.48\left(\mathrm{~s}, 3 \mathrm{H}, \mathrm{CH}_{3}\right)$; 3.66-3.94 (m, 8H, $\left.H_{\text {piperazine }}\right), 4.18\left(\mathrm{~s}, 2 \mathrm{H}, \mathrm{SCH}_{2}\right), 6.88\left(\mathrm{~d}, 1 \mathrm{H}, J=7.3 \mathrm{~Hz}, H_{\text {arom }}\right) ; 7.25(\mathrm{t}, 1 \mathrm{H}, J=$ $\left.7.0 \mathrm{~Hz}, H_{\text {arom }}\right) ; 7.48\left(\mathrm{t}, 1 \mathrm{H}, J=7.4 \mathrm{~Hz}, H_{\text {arom }}\right) ; 7.70\left(\mathrm{~d}, 2 \mathrm{H}, J=7.2 \mathrm{~Hz}, H_{\text {arom }}\right) ; 8.40(\mathrm{~d}, 1 \mathrm{H}, J=$ $7.5 \mathrm{~Hz},) .{ }^{13} \mathrm{C} \mathrm{NMR}\left(\mathrm{CDCl}_{3}\right): \delta 24.2\left(\mathrm{CH}_{3}\right) ; 33.0\left(\mathrm{SCH}_{2}\right) ; 41.5,45.5,48.5,48.9\left(C_{\text {piperazine }}\right) ; 116.7$ $\left(C_{\text {pyrimidine }}^{5}\right) ; 118.9,121.0,122.6,126.7\left(C_{\text {arom }}\right) ; 152.9\left(C_{\text {benzothiazole }}^{3 \mathrm{a}}\right) ; 156.9$ ( $\left.C_{\text {pyrimidine }}^{6}\right) ; 167.4$ $\left(\mathrm{C}=\mathrm{N}+C_{\text {pyrimidine-Me }}^{4} ; 168.0(\mathrm{C}=\mathrm{O}) ; 170.0\left(C_{\text {pyrimidine- }}^{2}\right)\right.$. Anal. calcd. for $\mathrm{C}_{18} \mathrm{H}_{19} \mathrm{~N}_{5} \mathrm{OS}_{2}$ : $\mathrm{C}$, 56.08; H, 4.97; N, 18.17. Found: C, 56.26; H, 4.76; N, 18.30. $m / z(E I) 385(\mathrm{M})^{+}$.

1-(4-(Benzo[d]thiazol-2-yl)piperazin-1-yl)-2-(5-methyl-1,3,4-thiadiazol-2-ylthio)ethanone (6d). From d (0.20 g). Yield: $0.30 \mathrm{~g}(77 \%)$; mp 176-178 ${ }^{\circ} \mathrm{C} .{ }^{1} \mathrm{H} \mathrm{NMR}\left(\mathrm{CDCl}_{3}\right): \delta 2.74(\mathrm{~s}, 3 \mathrm{H}$, $\left.\mathrm{CH}_{3}\right)$; 3.68-3.90 (m, 8H, $\left.H_{\text {piperazine }}\right), 4.40\left(\mathrm{~s}, 2 \mathrm{H}, \mathrm{SCH}_{2}\right), 7.18\left(\mathrm{t}, 1 \mathrm{H}, J=7.7 \mathrm{~Hz}, H_{\text {arom }}\right) ; 7.35(\mathrm{t}$, $\left.1 \mathrm{H}, J=7.7 \mathrm{~Hz}, H_{\text {arom }}\right) ; 7.63\left(\mathrm{~d}, 1 \mathrm{H}, J=7.1 \mathrm{~Hz}, H_{\text {arom }}\right) ; 7.70\left(\mathrm{~d}, 1 \mathrm{H}, J=7.2 \mathrm{~Hz}, H_{\text {arom }}\right) .{ }^{13} \mathrm{C}$ NMR $\left(\mathrm{CDCl}_{3}\right): \delta 15.7\left(\mathrm{CH}_{3}\right) ; 36.0\left(\mathrm{SCH}_{2}\right) ; 41.6,45.6,48.7,48.9\left(C_{\text {piperazine}}\right) ; 118.9,121.0,122.8$, $126.8,130.9\left(C_{\text {arom }}\right) \quad 141.0\left(C_{\text {thiophene }}^{5}\right) ; 152.8\left(C_{\text {benzothiazole }}^{3 \mathrm{a}}\right) ;\left(165.6\left(C_{\text {thiophene- }}^{2}\right), 165.8(\mathrm{C}=\mathrm{N})\right.$; 168.1 (C=O). Anal. calcd. for $\mathrm{C}_{16} \mathrm{H}_{17} \mathrm{~N}_{5} \mathrm{OS}_{3}$ : C, 49.08; $\mathrm{H}, 4.38 ; \mathrm{N}, 17.89$. Found: $\mathrm{C}, 49.36 ; \mathrm{H}$, 4.13; N, 18.00. $m / z(\mathrm{EI}) 391(\mathrm{M})^{+}$.

2-(1H-1,2,3-Triazol-5-ylthio)-1-(4-(benzo[d] thiazol-2-yl)piperazin-1-yl)ethanone (6e). From e $(0.17 \mathrm{~g})$. Yield: $0.12 \mathrm{~g}(33 \%) ; \mathrm{mp} 160-162{ }^{\circ} \mathrm{C} .{ }^{1} \mathrm{H}$ NMR $\left(\mathrm{CDCl}_{3}\right): \delta 3.16-3.63(\mathrm{~m}, 8 \mathrm{H}$, $\left.H_{\text {piperazine }}\right), 4.02\left(\mathrm{~s}, 2 \mathrm{H}, \mathrm{SCH}_{2}\right), 7.09(\mathrm{t}, 1 \mathrm{H}, J=7.3 \mathrm{~Hz}) ; 7.29\left(\mathrm{t}, 1 \mathrm{H}, J=7.3 \mathrm{~Hz}, H_{\text {arom }}\right) ; .47$ (d, $1 \mathrm{H}, J=8.0 \mathrm{~Hz}) ; 7.77\left(\mathrm{~d}, 1 \mathrm{H}, J=7.8 \mathrm{~Hz}, H_{\text {arom }}\right) ; 7.96(\mathrm{~s}, 1 \mathrm{H}) ; 12.21$ (brs., $\left.1 \mathrm{H}, \mathrm{NH}\right) .{ }^{13} \mathrm{C} \mathrm{NMR}$ $\left(\mathrm{CDCl}_{3}\right): \delta 37.1\left(\mathrm{SCH}_{2}\right) ; 41.3,45.2,48.1,49.4\left(C_{\text {piperazine}}\right) ; 119.2,121.9,122.1,124.0,126.5$, $130.4\left(C_{\text {arom }}+C_{\text {triazole }}^{4}\right) ; 139.5\left(C_{\text {triazole- }}^{5}\right) ; 152.8\left(C_{\text {benzothiazole }}^{3 \mathrm{a}}\right) ; 166.8(\mathrm{C}=\mathrm{N}) ; 168.5(\mathrm{C}=\mathrm{O})$. Anal. calcd. for $\mathrm{C}_{16} \mathrm{H}_{16} \mathrm{~N}_{6} \mathrm{OS}_{2}$ : C, 49.98; H, 4.47; N, 23.31. Found: C, 49.80; H, 4.54; N, 23.20. $m / z(\mathrm{EI}) 360(\mathrm{M})^{+}$.

1-(4-(Benzo $[d]$ thiazol-2-yl)piperazin-1-yl)-2-(1-methyl-1H-imidazol-2-ylthio)ethanone (6f). From f (0.18 g). Yield: $0.23 \mathrm{~g}(62 \%)$; mp 120-122 ${ }^{\circ} \mathrm{C} .{ }^{1} \mathrm{H} \mathrm{NMR}\left(\mathrm{CDCl}_{3}\right): \delta 3.70\left(\mathrm{~s}, 3 \mathrm{H}, \mathrm{CH}_{3}\right)$; 3.63-3.82 (m, 8H, $\left.H_{\text {piperazine }}\right), 4.16\left(\mathrm{~s}, 2 \mathrm{H}, \mathrm{SCH}_{2}\right) ; 6.96-7.64\left(\mathrm{~m}, 6 \mathrm{H}, H_{\text {arom }}\right) .{ }^{13} \mathrm{C} \mathrm{NMR}\left(\mathrm{CDCl}_{3}\right): \delta$ 
$33.5\left(\mathrm{CH}_{3}\right) ; 37.1\left(\mathrm{SCH}_{2}\right) ; 41.3,45.2,48.1,48.3\left(C_{\text {piperazine }}\right) ; 119.2,121.9,124.0,126.5,129.1$, $130.9\left(C_{\text {arom }}+C_{\text {imidazole })} ; 139.5 C_{\text {imidazole }}^{2}-\mathrm{S}\right) ; 152.8\left(C_{\text {benzothiazole }}^{3 \mathrm{a}}\right) ;\left(C_{\text {arom }}+; 166.8(\mathrm{C}=\mathrm{N}) ; 168.5\right.$ $(\mathrm{C}=\mathrm{O})$. Anal. calcd. for $\mathrm{C}_{17} \mathrm{H}_{19} \mathrm{~N}_{5} \mathrm{OS}_{2}$ : C, 54.67; H, 5.13; N, 18.75. Found: $\mathrm{C}, 54.65 ; \mathrm{H}, 4.94 ; \mathrm{N}$, 18.70. $\mathrm{m} / z(\mathrm{EI}) 373(\mathrm{M})^{+}$.

1-(4-(Benzo $[d]$ thiazol-2-yl)piperazin-1-yl)-2-(1-phenyl-1H-tetrazol-5-ylthio)ethanone (6g). From g (0.24 g). Yield: $0.38 \mathrm{~g}(86 \%) ; \mathrm{mp} 195-197{ }^{\circ} \mathrm{C} .{ }^{1} \mathrm{H}$ NMR $\left(\mathrm{CDCl}_{3}\right): \delta 3.68-3.83(\mathrm{~m}, 8 \mathrm{H}$, $\left.H_{\text {piperazine }}\right), 4.51\left(\mathrm{~s}, 2 \mathrm{H}, \mathrm{SCH}_{2}\right) ; 7.15-7.65\left(\mathrm{~m}, 9 \mathrm{H}, H_{\text {arom }}\right) .{ }^{13} \mathrm{C} \mathrm{NMR}\left(\mathrm{CDCl}_{3}\right): \delta 37.1\left(\mathrm{SCH}_{2}\right)$; 41.7, 45.5, 48.2, 48.2 ( $\left.C_{\text {piperazine }}\right) ; 119.4,120.9,122.2,123.7,126.4,129.9,130.3133 .5\left(C_{\text {arom }}\right)$; $154.0\left(C_{\text {tetrazole-S }}^{5}+C_{\text {benzothiazole }}^{3 \mathrm{a}}\right) ; 165.1(\mathrm{C}=\mathrm{N}) ; 168.1(\mathrm{C}=\mathrm{O})$. Anal. calcd. for $\mathrm{C}_{20} \mathrm{H}_{19} \mathrm{~N}_{7} \mathrm{OS}_{2}: \mathrm{C}$, 54.90; H, 3.83; N, 22.41. Found: C, 54.72; H, 3.88; N, 22.55. $\mathrm{m} / \mathrm{z}(\mathrm{EI}) 437(\mathrm{M})^{+}$.

2-(Benzo[d] oxazol-2-ylthio)-1-(4-(benzo[d] thiazol-2-yl)piperazin-1-yl)ethanone (6h). From $\mathbf{h}$ (0.22 g). Yield: $0.25 \mathrm{~g}(62 \%)$; mp 132-134 ${ }^{\circ} \mathrm{C} .{ }^{1} \mathrm{H} \mathrm{NMR}\left(\mathrm{CDCl}_{3}\right): \delta 3.68-3.93\left(\mathrm{~m}, 8 \mathrm{H}, H_{\text {piperazine }}\right)$, $4.40\left(\mathrm{~s}, 2 \mathrm{H}, \mathrm{SCH}_{2}\right), 7.15-770\left(\mathrm{~m}, 8 \mathrm{H}, H_{\text {arom }}\right) .{ }^{13} \mathrm{C} \mathrm{NMR}\left(\mathrm{CDCl}_{3}\right): \delta 35.7\left(\mathrm{SCH}_{2}\right) ; 41.56,45.5$, 48.7, $49.1\left(C_{\text {piperazine }}\right) ; 110.1$ ( $\left.C_{\text {oxazole }}^{7}\right) ; 118.4,118.8,120.0,120.6,121.1,123.0,124.2,124.5$, $127.0\left(C_{\text {arom }}+\left(C_{\text {oxazole }}\right) ; 141.6\left(C^{3 \mathrm{a}}\right.\right.$ oxazole $) ; 152.1\left(C_{\text {benzothiazole }}^{3 \mathrm{a}}\right) ; 164.0\left(C^{2}{ }_{\text {oxazole }} \mathrm{s}\right) ; 168.0(\mathrm{C}=\mathrm{O}$ $+\mathrm{C}=\mathrm{N})$. Anal. calcd. for $\mathrm{C}_{20} \mathrm{H}_{18} \mathrm{~N}_{4} \mathrm{O}_{2} \mathrm{~S}_{2}: \mathrm{C}, 58.52 ; \mathrm{H}, 4.42 ; \mathrm{N}, 13.65$. Found: $\mathrm{C}, 58.32 ; \mathrm{H}, 4.70$; $\mathrm{N}, 13.69 . \mathrm{m} / \mathrm{z}(\mathrm{EI}): 410(\mathrm{M})^{+}$.

1-(4-(Benzo $[d]$ thiazol-2-yl)piperazin-1-yl)-2-(benzo $[d]$ thiazol-2-ylthio)ethanone (6i). From i (0.23 g). Yield: $0.24 \mathrm{~g}(57 \%)$; mp $140-142{ }^{\circ} \mathrm{C} .{ }^{1} \mathrm{H}$ NMR $\left(\mathrm{CDCl}_{3}\right): \delta 3.70-3.90\left(\mathrm{~m}, 8 \mathrm{H}, H_{\text {piperazine }}\right.$ ), $4.45\left(\mathrm{~s}, 2 \mathrm{H}, \mathrm{SCH}_{2}\right), 7.28-7.85\left(\mathrm{~m}, 8 \mathrm{H}, H_{\text {arom }}\right) .{ }^{13} \mathrm{C} \mathrm{NMR}\left(\mathrm{CDCl}_{3}\right): \delta 35.6\left(\mathrm{SCH}_{2}\right) ; 41.5,45.6$, 48.9, 49.3 ( $\left.C_{\text {piperazine }}\right) ; 118.7,119.1,120.1,121.1,121.2,121.5,123.1,124.6,126.3,127.1 ; 135.1$ $\left(C_{\text {arom }}+C_{\text {thiadiazole }}\right) ; 152.7\left(C_{\text {benzothiazole }}^{3 \mathrm{a}}\right) ; 164.2\left(C_{\text {thiadiazole-s }}^{2}\right), 166.4(\mathrm{C}=\mathrm{N}) ; 168.0(\mathrm{C}=\mathrm{O})$. Anal. calcd. for $\mathrm{C}_{20} \mathrm{H}_{18} \mathrm{~N}_{4} \mathrm{OS}_{3}$ : C, 56.31; H, 4.25; N, 13.13. Found: C, 56.35; H, 4.06; N, 13.24. $\mathrm{m} / \mathrm{z}$ (EI) $426(\mathrm{M})^{+}$.

2-(1H-Benzo $[d]$ imidazol-2-ylthio)-1-(4-(benzo $[d]$ thiazol-2-yl)piperazin-1-yl)ethanone $\quad(6 \mathbf{j})$. From j $(0.22 \mathrm{~g})$. Yield: $0.25 \mathrm{~g}(61 \%)$; mp 100-102 ${ }^{\circ} \mathrm{C} .{ }^{1} \mathrm{H}$ NMR $\left(\mathrm{CDCl}_{3}\right): \delta 3.61-3.83(\mathrm{~m}, 8 \mathrm{H}$, $\left.H_{\text {piperazine }}\right), 4.32$ (s, $\left.2 \mathrm{H}, \mathrm{SCH}_{2}\right) ; 5.31$ (brs., $\left.1 \mathrm{H}, \mathrm{NH}_{2}\right) ; 7.13-7.65\left(\mathrm{~m}, 8 \mathrm{H}, H_{\text {arom }}\right) .{ }^{13} \mathrm{C}$ NMR $\left(\mathrm{CDCl}_{3}\right): \delta 34.4\left(\mathrm{SCH}_{2}\right) ; 41.7,45.9,47.9,48.2\left(C_{\text {piperazine }}\right) ; 119.5,120.9,121.0,122.0,122.1$, $123.2,125.4,126.1,126.2 ; 130.8\left(C_{\text {arom }}+C_{\text {benzimidazole }}\right) ; 138.7\left(C_{\text {benzimidazole }}^{3 \mathrm{a}}+C_{\text {benzimidazole }}^{7 \mathrm{a}}\right)$ $147.0\left(C_{\text {benzimidazole-s }}^{2}\right) ; 152.3\left(C_{\text {benzothiazole }}^{3 \mathrm{a}}\right) ; 167.7(\mathrm{C}=\mathrm{N}) ; 168.2(\mathrm{C}=\mathrm{O})$. Anal. calcd. for $\mathrm{C}_{20} \mathrm{H}_{19} \mathrm{~N}_{5} \mathrm{OS}_{2}$ : C, 58.66; H, 4.68; N, 17.10. Found: C, 58.72; H, 4.46; N, 17.09. m/z (EI) 409 $(\mathrm{M})^{+}$.

General procedure for the preparation of $N$-(5-Ethoxybenzo[d]thiazol-2-yl)-aryl- and methylsulfonamides (9b, 9l-n) and the 6-iodo analogue (10)

These compounds were prepared in a similar method for preparation of $\mathbf{5 a - k}$, by treatment of $\mathbf{7}$ and $8(1.00 \mathrm{mmol})$ with aryl- and methylsulfonyl chlorides $(\mathbf{b}, \mathbf{l}-\mathbf{n})(1.00 \mathrm{mmol})$. The products were recrystallized from $\mathrm{EtOH}$.

$\mathrm{N}$-(5-Ethoxybenzo[ $d \boldsymbol{d}$ thiazol-2-yl)-4-methylbenzenesulfonamide (9b). From b $(0.19 \mathrm{~g})$. Yield: 0. $0.26 \mathrm{~g}(76 \%) ; \mathrm{mp} 149-151{ }^{\circ} \mathrm{C} .{ }^{1} \mathrm{H}$ NMR $\left(\mathrm{CDCl}_{3}\right): \delta 1.30\left(\mathrm{t}, 3 \mathrm{H}, J=7.1 \mathrm{~Hz}, \mathrm{OCH}_{2} \mathrm{CH}_{3}\right) ; 2.40$ 
(s, 3H, $\left.\mathrm{CH}_{3}\right) ; 4.03$ (q, 2H, $J=7.1 \mathrm{~Hz}, \mathrm{OCH}_{2} \mathrm{CH}_{3}$ ); 4.89 (brs., $\left.1 \mathrm{H}, \mathrm{NH}\right) ; 6.97$ (dd, $1 \mathrm{H}, J=6.2 \mathrm{~Hz}$, $2.0 \mathrm{~Hz}, H^{6}$ benzothiazole); 7.35-7.63 (m, $\left.4 \mathrm{H}, H_{\text {arom }}\right)$; 7.87-8.01 (m, $2 \mathrm{H}, H_{\text {benzothiazole }}^{4}+H_{\text {benzothiazole }}^{7}$ ). ${ }^{13} \mathrm{C}$ NMR $\left(\mathrm{CDCl}_{3}\right): \delta 14.5\left(\mathrm{OCH}_{2} \mathrm{CH}_{3}\right) ; 21.2\left(\mathrm{CH}_{3}\right) ; 63.9\left(\mathrm{OCH}_{2} \mathrm{CH}_{3}\right) ; 104.8\left(\mathrm{C}_{\text {benzothiazole }}^{4}\right) ;$ 114.5 ( $C^{6}$ benzothiazole $) ; 121.6,122.4,128.6,130.4,136.1,137.9\left(C_{\text {arom }}\right) ; 152.1\left(C_{\text {benzothiazole }}^{5}\right) ; 149.3$ $\left(C^{3 \mathrm{a}}\right.$ benzothiazole $) ; 174.1(\mathrm{C}=\mathrm{N})$. Anal. calcd. for $\mathrm{C}_{16} \mathrm{H}_{16} \mathrm{~N}_{2} \mathrm{O}_{3} \mathrm{~S}_{2}: \mathrm{C}, 55.15 ; \mathrm{H}, 4.63 ; \mathrm{N}, 8.04$. Found: C, 54.92; H, 4.58; N, 7.87. m/z (FAB) $349(\mathrm{M}+\mathrm{H})^{+}$.

$\mathbf{N}$-(5-Ethoxybenzo[d]thiazol-2-yl)-2,4-nitrobenzenesulfonamide (91). From $\mathbf{l}(0.27 \mathrm{~g})$. Yield: 0.28 g (67\%); mp 193-194 ${ }^{\circ} \mathrm{C} .{ }^{1} \mathrm{H}$ NMR $\left(\mathrm{CDCl}_{3}\right): \delta 1.31\left(\mathrm{t}, 3 \mathrm{H}, J=7.0 \mathrm{~Hz}, \mathrm{OCH}_{2} \mathrm{CH}_{3}\right) ; 4.08(\mathrm{q}$, $\left.2 \mathrm{H}, J=7.0 \mathrm{~Hz}, \mathrm{OCH}_{2} \mathrm{CH}_{3}\right) ; 7.00\left(\mathrm{dd}, 1 \mathrm{H}, J=6.3 \mathrm{~Hz}, 2.1 \mathrm{~Hz}, H_{\text {benzothiazole }}^{6}\right) ; 7.88-8.05$ (m, 2H, $\left.H_{\text {benzothiazole }}^{4}+H_{\text {benzothiazole }}^{7}\right) ; 8.96-8.39\left(\mathrm{~m}, 3 \mathrm{H}, H_{\text {arom }}\right) .{ }^{13} \mathrm{C} \mathrm{NMR}\left(\mathrm{CDCl}_{3}\right): \delta 14.6\left(\mathrm{OCH}_{2} \mathrm{CH}_{3}\right)$; $64.1\left(\mathrm{OCH}_{2} \mathrm{CH}_{3}\right) ; 105.2\left(C_{\text {benzothiazole }}^{4}\right) ; 114.1\left(C^{6}\right.$ benzothiazole $+C^{3}$ arom $) ; 121.2,122.5,129.3,130.6$, $140.1\left(C_{\text {arom }}\right) ; 148.0\left(C_{\text {benzothiazole }}^{3 \mathrm{a}}+C_{\text {arom-NO2 }}^{2}\right) ; 152.1\left(C_{\text {benzothiazole }}^{5}+C_{\text {arom-NO2 }}^{4}\right) ; 174.3(\mathrm{C}=\mathrm{N})$. Anal. Calcd. For $\mathrm{C}_{15} \mathrm{H}_{12} \mathrm{~N}_{4} \mathrm{O}_{7} \mathrm{~S}_{2}$ : C, 42.45; H, 2.85; N, 13.20. Found: C, 42.23; H, 2.69; N, 12.97. $\mathrm{m} / \mathrm{z}(\mathrm{FAB}) 425(\mathrm{M}+\mathrm{H})^{+}$.

$\boldsymbol{N}$-(5-Ethoxybenzo $[\boldsymbol{d}]$ thiazol-2-yl)-1-benzylsulfonamide $(\mathbf{9 m})$. From $\mathbf{m}(0.19 \mathrm{~g})$. Yield: $0.26 \mathrm{~g}$ (75\%); mp 202-203 ${ }^{\circ} \mathrm{C} .{ }^{1} \mathrm{H}$ NMR $\left(\mathrm{CDCl}_{3}\right): \delta{ }^{1} \mathrm{H} \mathrm{NMR}\left(\mathrm{CDCl}_{3}\right): \delta 1.30$ (t, 3H, $J=7.2 \mathrm{~Hz}$, $\left.\mathrm{OCH}_{2} \mathrm{CH}_{3}\right) ; 4.10$ (q, 2H, $\left.J=7.2 \mathrm{~Hz}, \mathrm{OCH}_{2} \mathrm{CH}_{3}\right) ; 4.30$ (s, 2H, $\left.\mathrm{CH}_{2} \mathrm{Ph}\right) ; 6.97$ (dd, $1 \mathrm{H}, J=6.4 \mathrm{~Hz}$, $2.0 \mathrm{~Hz}, H^{6}$ benzothiazole); 7.23-7.37 (m, 5H, $\left.\mathrm{CH}_{2} P h\right) ; 7.85-7.98\left(\mathrm{~m}, 2 \mathrm{H}, H_{\text {benzothiazole }}^{4}+H_{\text {benzothiazole }}^{7}\right.$ ). ${ }^{13} \mathrm{C}$ NMR $\left(\mathrm{CDCl}_{3}\right): \delta 14.7\left(\mathrm{OCH}_{2} \mathrm{CH}_{3}\right) ; 64.2\left(\mathrm{OCH}_{2} \mathrm{CH}_{3}\right) ; 65.1\left(\mathrm{CH}_{2} \mathrm{Ph}\right) ; 104.9\left(\mathrm{C}_{\text {benzothiazole }}^{4}\right)$; $113.8\left(C^{6}\right.$ benzothiazole $) ; 121.0,122.3,129.0,128.4,130.8,133.0\left(C_{\text {arom }}\right) ; 148.5\left(C^{3 \mathrm{a}}\right.$ benzothiazle $) ; 152.4$ $\left(C^{5}\right.$ benzothiazole $) ; 173.9(\mathrm{C}=\mathrm{N})$. Anal. Calcd. For $\mathrm{C}_{16} \mathrm{H}_{16} \mathrm{~N}_{2} \mathrm{O}_{3} \mathrm{~S}_{2}: \mathrm{C}, 55.15 ; \mathrm{H}, 4.63 ; \mathrm{N}, 8.04$. Found: C, 54.90; H, 4.53; N, 7.85. m/z (FAB) $349(\mathrm{M}+\mathrm{H})^{+}$.

$\boldsymbol{N}$-(5-Ethoxybenzo[d] thiazol-2-yl)-methanesulfonamide (9n). From n $(0.12 \mathrm{~g})$. Yield: $0.17 \mathrm{~g}$ (60\%); mp 155-156 ${ }^{\circ} \mathrm{C} .{ }^{1} \mathrm{H}$ NMR $\left(\mathrm{CDCl}_{3}\right): \delta 1.29$ (t, 3H, $\left.J=7.0 \mathrm{~Hz}, \mathrm{OCH}_{2} \mathrm{CH}_{3}\right) ; 2.92$ (s, 3H, $\mathrm{SO}_{2} \mathrm{Me}$ ); 4.07 (q, 2H, J=7.0 Hz, $\left.\mathrm{OCH}_{2} \mathrm{CH}_{3}\right) ; 4.30$ (s, 2H, $\left.\mathrm{CH}_{2} \mathrm{Ph}\right) ; 6.99$ (dd, $1 \mathrm{H}, J=6.5 \mathrm{~Hz}, 2.1$ $\mathrm{Hz}, H^{6}$ benzothiazole $) ; 7.88\left(\mathrm{~m}, 1 \mathrm{H}, H^{7}\right.$ benzothiazole $) ; 8.02\left(\mathrm{~d}, 1 \mathrm{H}, J=6.5 \mathrm{~Hz}, H^{4}\right.$ benzothiazole $) .{ }^{13} \mathrm{C}$ NMR $\left(\mathrm{CDCl}_{3}\right): \delta 14.3\left(\mathrm{OCH}_{2} \mathrm{CH}_{3}\right) ; 64.4\left(\mathrm{OCH}_{2} \mathrm{CH}_{3}\right) ; 42.2\left(\mathrm{SO}_{2} \mathrm{Me}\right) ; 105.1\left(C_{\text {benzothiazole }}^{4}\right) ; 113.9$ $\left(C^{6}\right.$ benzothiazole $)$; 121.3, $\left(C^{7}\right.$ benzothiazole $+C^{7 \text { a }}$ benzothiazole $) ; 149.1\left(C_{\text {benzothiazole }}^{3 \mathrm{a}}\right) ; 152.6\left(C^{5}\right.$ benzothiazole $)$; $174.2(\mathrm{C}=\mathrm{N})$. Anal. Calcd. For $\mathrm{C}_{10} \mathrm{H}_{12} \mathrm{~N}_{2} \mathrm{O}_{3} \mathrm{~S}_{2}$ : C, 44.10; H, 4.44; N, 10.29. Found: C, 43.89; H, 4.37; N, 10.03. m/z (FAB) $299(\mathrm{M}+\mathrm{Na})^{+}$.

$\mathbf{N}$-(6-Iodobenzo[d] thiazol-2-yl)-2,4-nitrobenzenesulfonamide (10). From l (0.27 g). Yield: 0. $0.35 \mathrm{~g}(70 \%)$; mp 191-192 ${ }^{\circ} \mathrm{C} .{ }^{1} \mathrm{H}$ NMR $\left(\mathrm{CDCl}_{3}\right): \delta 7.50\left(\mathrm{~d}, 1 \mathrm{H}, J=6.6 \mathrm{~Hz}, H_{\text {benzothiazole }}^{4}\right)$; $9.01-$ $7.82\left(\mathrm{~m}, 5 \mathrm{H}, H_{\text {arom }}\right) .{ }^{13} \mathrm{C} \mathrm{NMR}\left(\mathrm{CDCl}_{3}\right): \delta 90.8\left(C^{6}{ }_{\text {benzothiazole }}\right) ; 114.3\left(C^{3}\right.$ arom-NO2$) ; 122.8,129.2$, 130.1, $131.1\left(C_{\text {arom }}\right) ; 140.0\left(C_{\text {arom-NO2 }}^{1}\right) ; 148.0\left(C_{\text {arom-NO2 }}^{2}\right) ; 151.8\left(C_{\text {benzothiazole }}^{3 \mathrm{a}}+C_{\text {arom-NO2 }}^{4}\right)$; $174.0(\mathrm{C}=\mathrm{N})$. Anal. Calcd. For $\mathrm{C}_{13} \mathrm{H}_{7} \mathrm{IN}_{4} \mathrm{O}_{6} \mathrm{~S}_{2}$ : C, 30.84; H, 1.39; N, 11.07. Found: C, 30.62; $\mathrm{H}$, 1.30; N, 10.91. $\mathrm{m} / \mathrm{z}(\mathrm{FAB}) 528 / 530(\mathrm{M}+\mathrm{Na})^{+}$.

\section{Cytotoxicity assays}

Cell cultures were seeded at $1 \times 10^{5}$ cells $/ \mathrm{ml}$ in 96 multiwell plates in specific media supplemented with $10 \% \mathrm{FCS}$ and antibiotics and incubated at $37{ }^{\circ} \mathrm{C}$ in a humidified $\mathrm{CO}_{2}(5 \%)$ 
atmosphere in the absence or presence of serial dilutions of test compounds. Cell viability was determined after $96 \mathrm{hrs}$ at $37{ }^{\circ} \mathrm{C}$ by the 3-(4,5-dimethylthiazol-2-yl)-2,5-diphenyl-tetrazolium bromide (MTT) method. $^{26}$

Compounds were dissolved in DMSO at $100 \mathrm{mM}$ and then diluted into culture medium.

\section{References}

1. Bradshaw, T. D.; Chua, M. S.; Browne, H. L.; Trapani, V.; Suasville, E. A.; Stevens, M. F. G. Br. J. Cancer 2002, 86, 1348.

2. Hutchinson, I.; Jennings, S. A.; Vishnuvajjala, B. R. ; Westwell, A. D.; Stevens, M. F. G. J. Med. Chem. 2002, 45, 744.

3. Leong, C. O.; Suggitt, M.; Swaine, D. J.; Bibby, M. C.; Stevens M. F. G.; Bradshaw, T. D. Mol. Cancer Ther. 2004, 3, 1565.

4. El-Sherbeny, M. A. Arzeneim. Forsch. 2000, 50, 848.

5. Shi, D.; Bradshaw, T. D.; Wrigley, S.; McCall, C. J.; Lelieveld, P.; Fichtner, I.; Stevens, M. F. G. J. Med. Chem. 1996, 37, 3375.

6. Bradshaw, T. D.; Wrigley, S.; Schultz, R. J.; Paull, K. D.; Stevens, M. F. G. Br. J. Cancer 1998, 77, 745.

7. Bradshaw, T. D.; Shi, D. F.; Schultz, R. J.; Paull, K. D.; Kelland. L.; Wilson, A.; Garner, C.; Fiebig, H. H.; Wrigley, S.; Stevens, M. F. G. Br. J. Cancer 1998, 77, 421.

8. Kashiyama, E.; Hutchinson, I.; Chua, M.-S.; Stinson, S. F.; Phillips, L. R.; Kuar, G.; Sausville, E. A.; Bradshaw, T. D.; Westwell, A. D.; Stevens, M. F. G. J. Med. Chem. 1999, 42, 4172, references therein cited.

9. Trapani, G.; Franco, M.; Latrofa, A.; Reho, A.; Liso, G. Eur. J. Pharm. Sci. 2001, 14, 209.

10. Srimanth, K.; Rao, V. R.; Krishna, D. R. Arzneim.-Forsch. 2002, 52, 388.

11. Watson, K. J.; Anderson, D. R.; Nguyen, S. T. Macromolecules 2001, 34, 3507.

12. Caleta, I.; Grdisa, M.; Mrvos-Sermek, D.; Cetina, M.; Tralić-Kulenović, V. K.; Pavelić, G.; Karminski-Zamola, G. Farmaco 2004, 59, 297.

13. Loaiza-Pérez, A. I.; Trapni, V.; Patel, V.; Hose, C.; Singh, S. S.; Trepel, J. B.; Stevens, M. F. G.; Bradshaw, T. D.; Sauville, E. A. Mol. Pharmacol. 2002, 61, 13.

14. Monks, A.; Harris, E.; Hose, C.; Connelly, J.; Sausville, E. A. J. Med. Chem. 2006, 49, 179.

15. Bradshaw, T. D; Bibby, M. C.; Double, J. A.; Fichtner, I.; Cooper, P. A.; Alley, M. C.; Donhue, S.; Stinson, S. F.; Tomaszewjski, J. E.; Suaville, E. A.; Stevens, M. F. G. Mol. Cancer Therap. 2002, 1, 239.

16. Trapni, V.; Patel, V.; Leong, C-O; Ciolino, H. P.; Yeh, G. C.; Hose, C.; Trepel, J. B.; Stevens, M. F. G.; Sauville, E. A.; Loaiza-Pérez, A. I. Br. J. Cancer 2003, 88, 599.

17. Mortimer, C. G.; Wells, G.; Grochard, J.-P., Stone, E. L.; Bradshaw, T. D.; Stevens, M. F. G.; Westwell, A. D. J. Med. Chem. 2006, 49, 179.

18. Wells, G.; Berry, J. M.; Bradshaw, T. D.; Burger, A. M.; Seaton, A.; Wang, B.; Westwell, A. 
D.; Stevens, M. F. G. J. Med. Chem. 2003, 46, 532.

19. Bradshaw, T. D.; Westwell, A. D. Curr. Med. Chem. 2004, 11, 1241.

20. Fichtner, I.; Monks, A.; Hose, C.; Stevens, M. F. G.; Bradshaw, T. D. Breast Cancer Res. Treat. 2004, 87, 97.

21. Yoshida, M.; Haykawa, I.; Hayshi, N.; Agatsuma, Kurakata, S. K.; Sugano, Y. Bioorg. Med. Chem. Lett. 2005, 15, 3328.

22. Racane, L.; Tralic-Kulenovic, V.; Fiser-Jakic, L.; Boykin, D. W.; Karminski-Zamola, G. Heterocycles 2001, 55, 2085.

23. Al-Soud, Y. A.; Al-Sa'doni, H. H.; Amjaour, H. A. S; Salih, K. S. M., Mubarak, M. S.; AlMasoudi; N. A. and Jaber, I. H. Z. Natufrorsch. 2008, 63b, 83.

24. Walczynski, K.; Guryn, R.; Zuiderveld, O. P.; Timmerman, H. Arch. Pharm. Pharm. Med. Chem. 1999, 332, 389.

25. Hose, C. D.; Hollingshead, M.; Sausville, E. A.; Monks, A. Mol. Cancer Ther. 2003, 2, 1265.

26. Pauwles, R.; Balzarini, J.; Baba, M.; Snoeck, R.; Schols, D.; Herdewijin, P.; Desmyster, J.; De Clercq, E. J. Virol. Methods 1988, 20, 309. 